East African Medical Journal Vol. 80 No. 8 August 2003

VISCERAL LEISHMANIASIS WITH CONCOMITTANT POST KALA-AZAR DERMAL LEISHMANIASIS RESPONDS TO ORAL SITAMAQUINE: CASE REPORT

J. Mbui, MBChB, MMed, MSc,Senior Research Officer, R. Rashid, MBChB, MMed, Principal Research Officer, H. Lodenyo, MBChB MMed, Senior Research Officer, P. Nyakundi, MBChB, MMed, Principal Research Officer, R. Kipmutai, MBChB, MMed, Research Officer, G. Mutuma, MBChB MMed, Principal Research Officer, G. Kirigi, Dip. Clin. Medicine, D. Kinoti, Higher National Dip, Clinical Officer and M. Wasunna, MBChB, MMed, PhD, Chief Research Officer, Center for Clinical Research, Kenya Medical Research Institute, P.O Box 54840, Nairobi, Kenya

Request for reprints to: Dr. J. Mbui, Centre for Clinical Research, Kenya Medical Research Institute, P.O. Box 54840, Nairobi, Kenya

\title{
VISCERAL LEISHMANIASIS WITH CONCOMITTANT POST KALA-AZAR DERMAL LEISHMANIASIS RESPONDS TO ORAL SITAMAQUINE: CASE REPORT
}

\author{
J. MBUI, R. RASHID, H. LODENYO, P. NYAKUNDI, R. KIPMUTAI, G. MUTUMA, G. KIRIGI, D. KINOTI \\ and M. WASUNNA
}

\section{SUMMARY}

\begin{abstract}
We report a rare case of visceral leishmanisis with concomitant post kala-azar dermal leishmaniasis as the initial presentation in a female patient from Baringo district, Rift valley province, Kenya.
\end{abstract}

\section{INTRODUCTION}

Visceral Leishmaniasis or kala-azar is caused by species of Leishmania donovani complex. These are Leishmania donovani donovani in East Africa and Asia, Leishmania donovani infantum in the Mediterranean Basin and Leishmania donovani chagasi in Latin America. Post kala-azar dermal leishmaniasis is a sequel to infection by L.donovani and presents with nodular skin lesions. A combination of both diseases as a first presentation is very rare and we believe it's the first time such an occurrence is being reported here in Kenya.

\section{CASE REPORT}

A 16 year old girl from Baringo district was admitted to Center for Clinical Research (CCR), Kenya Medical Research Institute (KEMRI) as a referral from Karbanet district hospital in June 2001 with complains of general body weakness, skin rash and abdominal swelling. Her medical problem had started in February 2001 with malarialike illness. She visited the local dispensary where she was diagnosed as a case of malaria and treated with anti malaria drugs. She however did not get better and the symptoms persisted and got worse. In March she noted that her abdomen was distended and soon after, developed a skin rash on the face. This time she visited a traditional healer who treated her with some herbs. Her condition continued to deteriorate to the extent that she opted out of school due the illness. She gave no history of previous attack of visceral leishmaniasis (VL) and her past medical history was not significant. On examination, she was sick looking, wasted and weighed $34 \mathrm{~kg}$. She had fever, temperature of $38^{\circ} \mathrm{C}$, was pale and she had pupular skin lesions on the face. Abdominal examination revealed splenomegaly of $15 \mathrm{~cm}$ below the costal margin but no ascites. Her other systems were essentially normal. In $\mathrm{CCR}$, the following tests were done: Haemogram: $\mathrm{Hb}$
$5.8 \mathrm{~g} / \mathrm{dl}$, WBC: $3.6 \times 10^{3} / \mathrm{mm}^{3}$ granulocytes $29 \%$, lymhocytes $71 \%$, eosinophils $0 \%$, monocytes $0 \%$, basophils $0 \%$. Platelets- $93 \times 10^{3} / \mathrm{mm}^{3}$, peripheral blood film, no malaria parasites were seen, prothombin test of 25 seconds, control 15.2 seconds. Blood chemistry: AST 51 $\mathrm{U} / \mathrm{L}$, ALT 24U/L, protein 116g/1, albumin 23.4g/l, globulin $83.5 \mathrm{~g} / \mathrm{l}$, urea $3.8 \mathrm{mmol} / \mathrm{l}$, creatinine $116 \mathrm{umol} / 1$. Splenic aspiration could not be done due to prolonged prothombin time of 25 seconds compared to control of 15 seconds. Therefore a bone marrow aspirate was done and revealed amastigotes $(3+)(1)$. Three slit skin smears of the facial lesions were also done and found to have amastigotes as well (1+). A diagnosis of visceral leishmaniasis with concomitant post-kala-zar dermal leishmaniasis (PKDL) was made (Figure1).

\section{Figure 1}

Patient seen on admission with typical lesions of PKDL. Skin slit smears confirmed presence of amastigotes while a bone marrow aspirate confirmed VL 


\section{Figure 2}

Patient seen at six months follow-up after successful
treatment. Bone marrow smear were negative for
leishmania amastigotes and PKDL lesions had cleared

Figure 3

Patient seen after one year of follow-up come again after six months for a follow-up assessment.

At six months follow-up, the patient had no complaints and was found to be in good general condition. She had added weight by $5 \mathrm{~kg}$ from $40 \mathrm{~kg}$ on discharge to $45 \mathrm{~kg}$ at 6 months follow up. The skin lesions had disappeared and she had no palpable spleen and a bone marrow aspirate was negative for amastigotes. Her haematological profile showed an increase of all parameters including the appearance of eosinophils. It was as follows: $\mathrm{Hb} 11.2 \mathrm{~g} / \mathrm{dl}$, WBC $5.0 \times 10^{3}$, (granulocytes $38 \%$, lymphocytes $57 \%$, eosinophils $3 \%$ monocytes $2 \%$ basophils $0 \%$ ). Platelets- $153 \times 10^{3} / \mathrm{mm} /$ $\mathrm{mm}^{3}$, peripheral blood film, no malaria paraites seen. Blood chemistry: AST $43 \mathrm{U} / 1$, ALT 35U/1, protein 92.4g/ 1 , albumin $30.5 \mathrm{~g} / 1$, globulin $61.5 \mathrm{~g} / \mathrm{l}$, urea $4.1 \mathrm{mmol} / 1$, creatinine $106 \mathrm{umol} / \mathrm{l}$. A bone marrow aspirate was negative for amastigotes. The patient was therefore declared cured and discharged from the study as the follow up period in this study was six months. However due to the presence of skin lesions of PKDL in addition to VL, it was felt that the follow up period for this particular patient be extended to one year.

At one year follow-up, patient was found to be in good general condition and the facial lesions of PKDL had completely cleared. The spleen was not palpable and her weight at one year of follow-up was $44 \mathrm{~kg}$. A bone marrow aspirate was negative for amastigotes. The photographs of the patient seen at six months and at one year follow-up are seen (Figures 1 and 2).

\section{DISCUSSION}

Visceral leishmaniasis s usually spread to man through the bite of a female sandfly vector of the genus phlebotomous. In Kenya, the endemic foci of visceral leishmaniasis or kala-azar include Baringo, Koibatek, Turkana, West Pokot, Kitui, Meru, Mwingi and Machakos districts. The disease often presents with fever, general malaise, weight loss and a distended abdomen caused by an enlarged spleen. Clinical signs include parlor and hepatosplenomegaly, while haematological parameters show a pancytopeanic picture.

Post kala-azar dermal leishmaniasis is usually a sequel of infection by $L$. donovani. The disease is characterised by skin a lesion ranging from hypopigmented macules to nodules over the face and trunk mimicking the skin lesions of leprosy. Most patients with PKDL give a history of previous treatment of VL or a self-healing febrile illness compatible with VL. There are however a few patients who give no history of an attack of VL like this particular case. In Kenya, the disease occurs shortly after, or a few months after completing treatment. The attack rate is about 2-5\% and patients respond well to the standard therapy (3). The standard treatment for PKDL in Kenya is similar to VL which is pentostam ${ }^{\circledR} 20 \mathrm{mg} / \mathrm{kg}$ for 30 days, but the former requires a longer duration of treatment(4). PKDL patients are infectious to the sandflies and are thought to play a major reservoir role in disease transmission between epidemics (5). for amastigotes. Haemoglobin levels were $8.2 \mathrm{gm} / \mathrm{dl}$ and platelets were $141 \times 10^{3} / \mathrm{mm}^{3}$. The patient was discharged to 
Visceral leishmaniasis occurring concurrently with PKDL is a rare presentation, and this is the first time such a presentation is being reported in Kenya. It is even more rare for the two diseases to occur together as an initial presentation. However there are a few cases reported in the literature of recurrence of VL accompanied by PKDL mainly in India (6-8). In all these cases, VL was initially treated and cured then reappeared many years after most likely due to re-infection accompanied by lesions of PKDL. It is also important to note that this is the first case we are reporting from Kenya where an oral antileishmanial drug has successfully treated a case with PKDL.

Sub typing of the parasite genome has not been done to confirm whether the parasite that caused the two different clinical manifestations was the same but we plan to do it in the near future.

\section{ACKNOWLEDGEMENTS}

To the Director, KEMRI for allowing this paper to be published, GlaxoSmithKline, the sponsors of the study, and all nurses and laboratory staff from the Center for Clinical Research for their contribution in managing the patient.

\section{REFERENCES}

1. Chulay, J.D., and Brycesson A.D.M. Quantifications of amastigotes of leishmania donovani in smear of splenice aspirates of patients with visceral leishmaniasis. Am. J. Trop. Med. Hyg. 1983; 3: 2

2 Wasunna M., Lodenyo H., Mbui J., et al. Sitamaquine (SB252220, WR 6026) in the oral treatment of visceral leishmaniasis. The second World congress on Leishmaniasis, Crete, Greece. Abstract no. 125, 2001.

3 Rashid J.R., Chunge C.N., Oster C.N. et al. PKDL occurring long after cure of VL in Kenya. East Afr. Med. J. 1986; 63: 365-367.

4. Muigai R., Gachihi G.S., and Oster C.N. Post kala-azar dermal leishmaniasis, the Kenyan experience. East Afr. Med. J. 1991; 68:801-806

5. Addy M., and Naddy A. Ten years of kala-azar in West Bengal, part 1. Did post Kala-azar dermal leishmnaisis initiate the out break in 24-Parganas? Bull. World Health Organ., 1992; 70:341-346

6. Singh N.K.P., Agrrawal S.K., and Jha T.K. Visceral leishmaniasis associated with post kala-azar dermal leishmaniasis. J. Assoc. Physicians of India 1989; 37:191.

7. Sen gupta P.C., and Mukherjee A.M. Recurrence of kala-zar asociated with post-kaalzar dermal leishmaniasis. J. Indian Med. Assoc. 1968; 50:1-7.

8. Sharma V.K., and Jha T.K. Recurrence of kala-azar in a case of post kala-azar dermal leishmaniasis. Indian J. Dermal. Vernerol. Leprosy. 1985; 51:259-260. 